\title{
The conundrum of iron in multiple sclerosis - time for an individualised approach
}

\author{
Susan J. van Rensburg • Maritha J. Kotze • \\ Ronald van Toorn
}

Received: 28 November 2011 / Accepted: 23 February 2012/Published online: 17 March 2012

(C) Springer Science+Business Media, LLC 2012

\begin{abstract}
Although the involvement of immune mechanisms in multiple sclerosis (MS) is undisputed, some argue that there is insufficient evidence to support the hypothesis that MS is an autoimmune disease, and that the difference between immune- and autoimmune disease mechanisms has yet to be clearly delineated. Uncertainties surrounding MS disease pathogenesis and the modest efficacy of currently used disease modifying treatments (DMTs) in the prevention of disability, warrant the need to explore other possibilities. It is evident from the literature that people diagnosed with MS differ widely in symptoms and clinical outcome - some patients have a benign disease course over many years without requiring any DMTs. Attempting to include all patients into a single entity is an oversimplification and may obscure important observations with therapeutic consequences. In this review we advocate an individualised approach named Pathology Supported Genetic Testing (PSGT), in which genetic tests are combined with biochemical measurements in order to identify subgroups of patients requiring different treatments. Iron dysregulation in MS is used as an example of how this approach may benefit
\end{abstract}

\section{S. J. van Rensburg $(\bowtie)$}

Division of Chemical Pathology, National Health Laboratory

Service and University of Stellenbosch, Tygerberg Hospital,

PO Box 19113, 7505 Tygerberg, South Africa

e-mail: sjvr@sun.ac.za

\section{J. Kotze}

Division of Anatomical Pathology, Department of Pathology, University of Stellenbosch,

Western Cape, South Africa

R. van Toorn

Department of Paediatrics and Child Health,

University of Stellenbosch,

Western Cape, South Africa patients. The theory that iron deposition in the brain contributes to MS pathogenesis has caused uncertainty among patients as to whether they should avoid iron. However, the fact that a subgroup of people diagnosed with MS show clinical improvement when they are on iron supplementation emphasises the importance of individualised therapy, based on genetic and biochemical determinations.

Keywords Myelin · Autoimmunity · Biochemistry . Genetics $\cdot$ Personalised medicine

\section{Introduction}

Whether iron supplementation is beneficial or harmful to people with multiple sclerosis (MS) has been debated for several years. The answer is of critical importance as it may guide physicians to optimal treatment of a very complex disorder (van Rensburg and van Toorn 2010). The intensity of the iron-MS debate escalated substantially when Dr Paolo Zamboni, a vascular surgeon, presented a hypothesis to the Royal Society of Medicine that iron deposition in the brain may contribute to the development of MS (Zamboni 2006). This theory states that periventricular iron deposits are formed in the brain, similar to those that form around veins in the leg in chronic deep vein thrombosis. Iron released from the deposits may cause oxidative damage resulting in the recruitment of white blood cells into the brain matrix (Singh and Zamboni 2009). The deposits are thought to result from an inhibition of blood outflow from the brain through the jugular veins due to venous obstructions. The hypothesis is called chronic cerebrospinal venous insufficiency (CCSVI), and it is suggested that balloon dilatation or stents may be used to improve cerebral venous drainage. 
The hypothesis and procedure were received with much scepticism by the majority of the medical community. The Cardiovascular and Interventional Radiological Society of Europe (CIRSE) issued a commentary (Reekers et al. 2011) in which they expressed the belief that the lack of clinical trial data did not offer a sound basis for such treatments. Filippi et al. (2011) stated that clinicians were generally satisfied with the current prevailing theory of MS, and since some studies have not confirmed the original results, "endovascular treatment of presumed vascular abnormalities in MS should be discouraged vigorously".

The hypothesis however generated much optimism amongst people with MS, since correction of cerebral venous drainage is anecdotally related to rapid improvement in clinical outcome (reduced disability). Public urgency led the US National MS Society to fund a number of independent studies to investigate the relationship between CCSVI and MS. The above scenario emphasises the complexity of MS research, the diversity of treatment modalities available and the uncertainty all of this creates among MS sufferers. Evidence of this uncertainty is seen on the Internet where patients and MS support groups actively communicate with one another via Facebook, YouTube and blogs, raising optimism for "liberation treatment", as the CCSVI treatment is called, contrary to the advice of clinicians (Filippi et al. 2011).

This raises the question: Is this not the time for the medical fraternity to acknowledge patient perception that conventional medicine does not benefit all patients? Recent studies, for example, found that fewer than half of patients benefit from interferon- $\beta$, one of the standard treatments for MS (Byun et al. 2008; Wekerle and Hohlfeld 2010). In non-responders, interferon- $\beta$ may even cause worsening of disease outcome due to a Th17 immune response (Axtell et al. 2011). Treatment with disease modifying agents has been shown to reduce relapse rates, but has limited effect on disability progression. Such medications often have unpleasant side effects (Walther and Hohlfeld 1999), and patient resistance to taking the injections is not infrequently reported (Hancock et al. 2011). Unfortunately, these findings are not always reflected in randomised controlled trials, which may be attributed to selection bias, i.e. enrollment of an enriched study sample that differs from true population-based samples (Pittock and Rodriguez 2008; Caplan 2011). The controversies surrounding disease pathogenesis in MS and lack of efficacy of the currently used disease modifying agents to prevent disability, warrant the need to re-explore MS disease mechanisms, such as gaining an in-depth understanding of the basic biochemical processes that take place during demyelination. This would include the role played by genetic defects and biochemical deficiencies, and subsequent intervention to alleviate them. Investigating the role of iron in MS is especially important due to the uncertainty of whether it is safe for MS patients to take iron supplements, or whether they should avoid ingesting iron.

\section{Is iron harmful or helpful in MS?}

Proponents of the "iron is harmful" theory advocate reduced iron intake or removal of iron by chelation therapy as a means of reducing iron deposition in the brain (LeVine and Chakrabarty 2004). Their justification is based on the fact that poorly liganded iron generates free radicals via the Fenton reaction that could damage various molecules and tissues, including myelin (Kell 2009). Much of the research in this field is performed on an animal model of brain inflammation, experimental allergic (more recently: autoimmune) encephalomyelitis (EAE), which is widely believed to be a model for MS. EAE is generated by injecting an animal with an antigen such as myelin basic protein, together with an adjuvant such as Mycobacterium tuberculosis and pertussis toxin. In a study frequently cited to prove the benefit of iron deprivation, mice did not develop EAE when they were fed a low-iron diet (Grant et al. 2003). However, the authors did point out that the severity of EAE was not exacerbated in mice that were fed a high iron diet, and that the positive outcome of the iron deprivation was related to the impairment of CD4+ $\mathrm{T}$ cell development, rather than having a central effect. Furthermore, the authors emphasised that the potential harmful consequences of iron deficiency anaemia should preclude the translation of this research to humans, a warning that has not always been heeded.

Iron deprivation in MS would have been justified if substantiated by studies demonstrating improved disease outcome in people with MS who were iron restricted as in the case of the EAE animals. However, a clinical trial involving 9 chronic progressive patients with MS, who received up to 8 courses of the iron chelator desferrioxamine over 2 years, had a variable outcome (Lynch et al. 2000). One patient improved, 3 remained stable, and 5 worsened on the Expanded Disability Status Scale (EDSS) (Kurtzke 1983), the "gold-standard test" for neurological outcome. The authors attributed the negative outcome of the chelation therapy to an inadequate dosage schedule (Lynch et al. 2000). However, a more plausible explanation is that EAE is not a model for human MS (Sriram and Steiner 2005). It was designed to be an animal model for autoimmunity years ago, when it was first postulated that MS was an autoimmune disease (Behan and Chaudhuri 2010). Rodriguez (2009) has however pointed out that it is extremely difficult to classify MS as an autoimmune disease, since extensive research over more than 50 years has failed to confirm that MS fulfills the criteria for autoimmunity as proposed by Schwartz and Datta (1989; Table 1). A comparison with 
Table 1 Criteria for determining a disease as autoimmune

Table adapted from Rodriguez M. Have we finally identified an autoimmune demyelinating disease? Ann Neurol. 2009; 66 (5):572-573. Reproduced with permission of John Wiley \& Sons, Inc
1. Demonstration of an immune response to a precise autoantigen in all patients with the disease
2. Reproduction of the lesion by administration of autoantibody or T cells into a normal animal
3. Induction of lesion by immunizing an animal with relevant purified autoantigen
4. Isolation or presence of autoantibody or autoreactive $\mathrm{T}$ cell from lesion (or serum)
5. Correlation of autoantibody or autoreactive $\mathrm{T}$ cell with disease activity
6. Presence of other autoimmune disorders or autoantigens associated with disease
7. Immune absorption with purified autoantigen abrogates pathogenic autoantibody or autoreactive $\mathrm{T}$ cell
8. Reduction of pathogenic autoantibody or T cell associated with clinical improvement

neuromyelitis optica shows that whilst the latter fulfills these criteria, MS does not (Rodriguez 2009).

\section{Mind the gap}

The autoimmune hypothesis, based to a large extent on results obtained with EAE, states that potentially autoaggressive $T$ cells exist in the blood of patients with MS, having been activated by an antigen that mimics myelin proteins. These $\mathrm{T}$ cells then traverse the blood-brain barrier (BBB) and migrate into the central nervous system (CNS) where they "orchestrate a complex series of interactions culminating in the destruction of both myelin and axons" (Hohlfeld 2010). A huge amount of literature, becoming ever more complex, exists in this field, although "there is still a wide gap between research in human MS and its animal models" (Hohlfeld 2010). The reason for this gap is that the 8 criteria for autoimmunity (Table 1) are all based on the premise that a precise autoantigen should be identified for the disease, similar to rheumatoid factor in rheumatoid arthritis. However, such an antigen has not yet been found in MS (Rodriguez 2009). While several self- and environmental antigens activate immune cells in patients with MS (Kimball et al. 2011), none of them meet the criteria listed in Table 1. In EAE the antigen is provided by the researcher, who decides which of the myelin proteins to inject. Therefore, the evidence for autoimmunity in MS remains elusive (Behan and Chaudhuri 2010; Steiner and Mosberg-Galili 2010; Trapp 2004; Miravalle and Corboy 2010; Corthals 2011). In addition, it has been shown that the oligoclonal B-cell response in the cerebrospinal fluid (CSF) of patients with MS is not targeted against the myelin proteins generally thought to direct the autoimmune attack: myelin basic protein, proteolipid protein, or myelin oligodendrocyte glycoprotein (Owens et al. 2009). Therefore, although the involvement of immune mechanisms in MS is confirmed (The International Multiple Sclerosis Genetics Consortium \& the Wellcome Trust Case Control Consortium 2011), this does not necessarily provide proof for autoimmunity. Since there appears to be a general misunderstanding regarding the difference between immune- and autoimmune disease mechanisms, Table 1 may help to stimulate discussion in this regard.
The evidence for immune involvement in MS is that alleles of the major histocompatibility complex (MHC) exert the single strongest genetic effect in MS disease susceptibility (Ramagopalan and Ebers 2009; Ramagopalan et al. 2009). MHC molecules usually present antigen to CD4+ T cells. However, it was demonstrated in mice that Class II MHC molecules could exacerbate demyelination independently of T cells (see below) (Hiremath et al. 2008), indicating that there may be other mechanisms besides autoimmunity by which the immune system may exert negative effects. It may be possible that the immune response in MS is secondary to a primary disease mechanism residing within the CNS (Trapp 2004). For example, in people predisposed to MS, EpsteinBarr virus (EBV) (Levin et al. 2010) and other infections may activate the human endogenous retrovirus (HERV), thereby producing active virus particles which may in turn activate the immune system (Perron and Lang 2010).

Contemplating the possibility that MS may not be an autoimmune disease after all requires a huge mind shift, since autoimmunity in MS has become an entrenched dogma over the years. The assumption of MS as autoimmune has created a mindset of a typically progressive disabling condition which is incurable, since the origin of the disease emanates from a permanently dysfunctional immune system. Accordingly, the only hope is to delay disease progression by de-activating the immune system or to stop peripheral immune cells from entering the brain by using disease modifying treatments (DMTs). However, the autoimmune hypothesis cannot explain "benign" MS, defined as patients who have an EDSS score of 3 or less after 10 years, and have a $>90 \%$ chance of remaining free from disability for $>20$ years without taking DMTs (Pittock et al. 2004; Mastorodemos et al. 2010). The number of patients having a favorable disease outcome may be significant, up to $30 \%$ (Pittock and Rodriguez 2008).

Besides benign MS, four subtypes of MS were standardised in 1996: relapsing-remitting- (RRMS), secondary progressive- (SPMS), primary progressive- (PPMS) and progressive relapsing MS (Lublin and Reingold 1996). However, despite attempts to classify disease subtypes, the diagnosis of MS remains confusing due to the heterogeneity of the disease (Steiner and Mosberg-Galili 2010). 


\section{Individualised treatment for subgroups of MS?}

Are other disease mechanisms involved in MS besides autoimmunity? Apart from CCSVI, several other hypotheses have been put forward. It could be argued that the demyelination in MS should be considered a common endpoint originating from different etiologies, thus emphasizing the importance of individualised therapy requirements (Fig. 1). The role of iron in MS illustrates this concept. Over the last 15 years our research has identified a subgroup of patients who, having presented with low iron parameters at diagnosis, subsequently followed a benign disease course only when the iron deficiency was alleviated through continuous lifelong supplementation (Kotze and Rooney 1997; Rooney et al. 1999; Kotze et al. 2001; van Rensburg et al. 2006; van Toorn et al. 2010). These patients are often non-anaemic iron deficient; therefore it is not sufficient to test for anaemia, neither does a ferritin determination alone suffice. It is not known whether this subgroup represents "true" MS, since they evidently have a metabolic inability to adequately absorb the iron required for myelin maintenance (Kotze et al. 2001); however, they are clinically indistinguishable from MS. Notably, iron deficient pediatric patients, who present with extensive demyelination at diagnosis, respond particularly well to this treatment (van Toorn et al. 2010). This finding is very encouraging, sparing children the potential harmful side effects of immunomodulators. Care should be taken to prevent constipation in patients requiring long-term iron maintenance therapy by prescribing an appropriate iron formulation. It is furthermore important to appreciate that iron deficiency may be only one component of a complex picture encompassing genetic predisposition and environmental factors causing apoptosis of oligodendrocytes (the cells that produce and maintain myelin in the brain - see below), and subsequent demyelination (Fig. 1).

The accuracy of serum iron determination has been debated, primarily because of diurnal variation (Dale et al. 2002); therefore standardisation of iron determinations by blood collection method and time, by comparing different iron parameters, i.e. serum iron, transferrin (Tf) saturation and ferritin, and by repeating all determinations at follow-up are of critical importance. It is furthermore essential not only to identify patients with overt, unmistakable iron deficiency, but also those with moderate iron deficiency, as they may also clinically benefit from supportive iron supplementation. The previously published MS study population is representative of what we routinely find: high serum iron levels, although occurring in some patients, are not the norm (van Rensburg et al. 2006); about a third of patients have low serum iron $(<10 \mu \mathrm{mol} / \mathrm{l})$ while $20 \%$ of the patients have very low levels consistently over many years if they do not take iron supplements. This may be related to environmental circumstances such as diet, or variations in the genes coding for iron uptake proteins.

To our knowledge iron deficiency in MS is a novel finding, since other researchers relate MS to iron excess even if their results may suggest otherwise. For example, increased soluble transferrin receptors (sTfR) in MS, attributed to increased iron turnover (Sfagos et al. 2005) could alternatively signify iron deficiency (Suominen et al. 1998); calculating the sTfR/log ferritin ratio (TfR-F Index) could help to distinguish between these two concepts. If iron does play a role in the aetiology of MS, it may well be that some
Fig. 1 Flow diagram of a hypothesis for genetic and environmental factors determining the aetiology and disease progression of multiple sclerosis. Figure adapted from Van Rensburg et al. 2009/2010. Multiple Sclerosis. In: MIMS Disease Review 2009/2010. Reproduced with permission of Avusa Media Limited

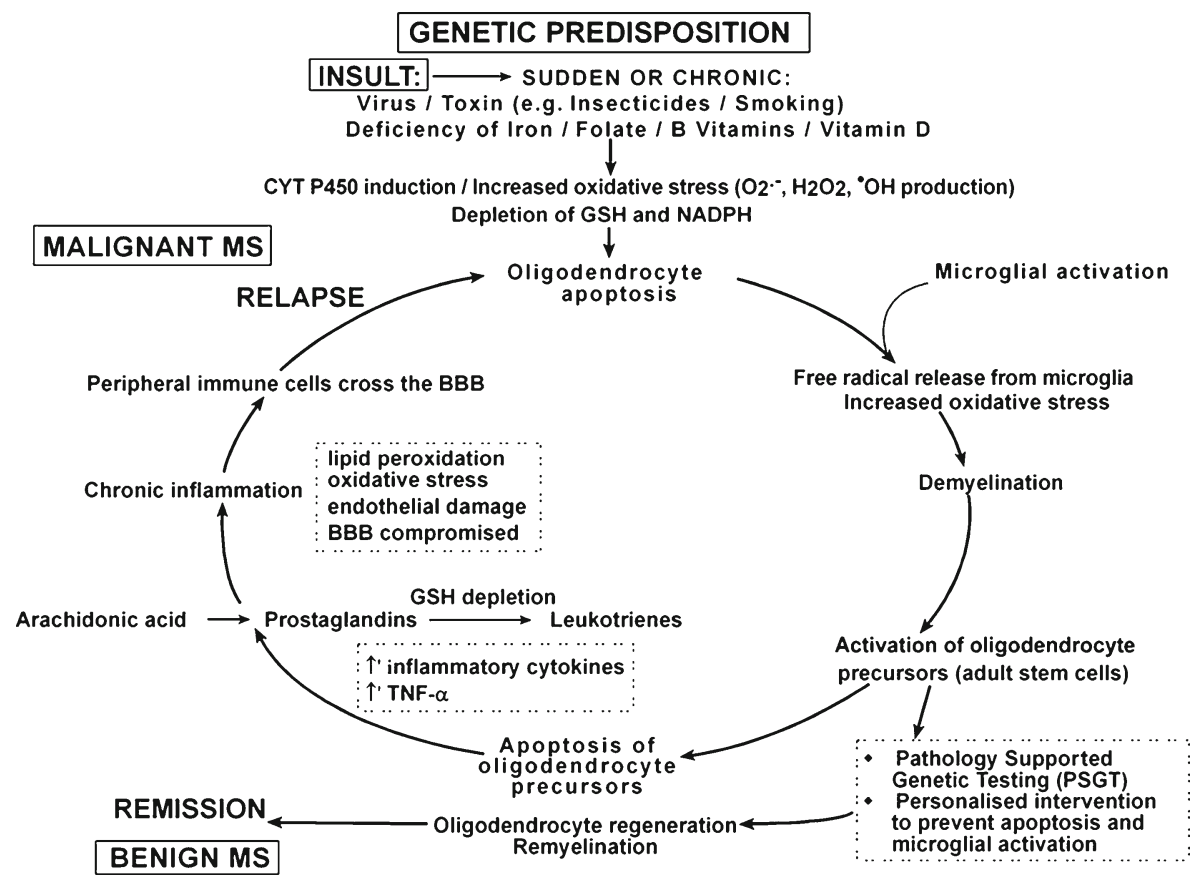


patients may need supplementation, and others attenuation of iron intake depending on their genetic make-up, making the treatment of patients with MS particularly amenable to the concept of Pathology Supported Genetic Testing (PSGT), involving genetics as well as biochemical determinations (Kotze et al. 2010).

\section{The hypothesis of oligodendrocyte apoptosis}

The role of iron in MS may be linked to an important alternative hypothesis for the aetiology of MS. Investigations of early MS brain lesions by Barnett and Prineas (2004) showed evidence of apoptosis (controlled cell death) of oligodendrocytes, leading to the extensive demyelination seen at diagnosis and during relapses. In early lesions the demyelination is initiated not by peripheral immune cells, but by microglia, the immune cells resident in the brain. During apoptosis, phosphatidylserine is externalised on cell membranes, which acts as an 'eat me' signal to phagocytes such as microglia (Barnett et al. 2006). The activated microglia clear the demised oligodendrocytes and the resulting dysfunctional myelin from the axons (Barnett and Prineas 2004). Subsequently, peripheral macrophages are recruited into the brain as scavengers, amplifying the inflammatory response (Barnett et al. 2006). Remarkable is the fact that oligodendrocyte precursors (adult stem cells) were observed in the immediate vicinity of the apoptotic process (Barnett and Prineas 2004). These cells, resident in the brain, mature into new oligodendrocytes and remyelinate the axons.

These findings have important clinical implications for disease outcome in MS since remyelination of the axons by oligodendrocyte precursor cells (OPCs) would induce remission and restoration of function, whilst lack of survival of these cells would lead to progressive myelin loss, neuronal injury and clinical disability.

Several questions arise:

(1) What causes oligodendrocyte apoptosis?

(2) Is oligodendrocyte demise preventable?

(3) Can remission be achieved and sustained by preventing oligodendrocyte cell death and promoting OPC survival and maturation?

From a biochemical point of view, oligodendrocyte apoptosis may be caused by several factors (Fig. 1): (1) infective agents, (2) inflammatory mediators such as cytokines (Cammer 2002), (3) poisons or toxins, e.g. components of cigarette smoke (Healy et al. 2009), (4) deficiencies of essential nutrients (van Rensburg et al. 2006), (5) oxygen radicals (Kim and Kim 1991), depletion of antioxidants and oxidative stress leading to the release of ceramide (Jana and Pahan 2007), or (6) mitochondrial failure (Ly et al. 2003).
Iron may play a role in all of these insults as both iron overload and iron depletion can induce apoptosis, albeit by different mechanisms (Fassl et al. 2003). While iron excess may increase oxidative stress, iron depletion causes an energy deficit and loss of membrane potential in mitochondria (Koc et al. 2005). During infection/inflammation, iron is sequestered by the immune system to overcome the infection and may therefore decrease the availability of iron to oligodendrocytes. Iron deficiency may paradoxically also generate free radicals (van Rensburg et al. 2004). Catalase, one of the foremost antioxidant enzymes in oligodendrocytes contains 4 haem groups; its production and maintenance is therefore dependent on a constant supply of iron. If the catalase antioxidant system fails, oligodendroglial cell death may follow (Kim and Kim 1991). Furthermore, ingestion of medication or toxic substances causes the induction of cytochrome P450 which would suddenly have to be mass-produced to metabolise these chemicals. Iron deficiency could inhibit this process since each cytochrome P450 molecule contains a haem group.

The hypothesis of oligodendrocyte apoptosis unlocks the possibility that the MS disease process may be influenced by meeting the metabolic requirements of oligodendrocytes. While these cells are extremely complex, their needs for survival may be relatively simple to comprehend, since they have been studied extensively and a wealth of information already exists in the literature.

\section{Iron requirement by oligodendrocytes}

The essential requirement for iron in oligodendrocytes has been systematically investigated in NIH-funded research by the group of Connor since the 1980's. They showed that staining normal brain tissue with a dye that detects iron, identifies oligodendrocytes as the main iron-containing cells in the brain and that under normal circumstances these cells accumulate iron (Gerber and Connor 1989). Oligodendrocytes need iron for the extremely high energy requirements of producing and maintaining the complex myelin sheath which is many times larger than the cell body (Connor and Menzies 1996), indicating that iron deficiency could seriously compromise the viability of these cells. The list of iron-requiring enzymes in oligodendrocytes is extensive (Todorich et al. 2009). Myelin consists mainly of lipids and proteins synthesised by the oligodendrocytes themselves for their own requirements. Iron is essential for many of these biochemical reactions, such as cholesterol synthesis, which occurs at a higher rate in oligodendrocytes than any other cell type in the brain (Pleasure et al. 1977).

Iron is also a prerequisite for the maturation of OPCs into oligodendrocytes (Morath and Mayer-Pröschel 2001;2002), while $\mathrm{Tf}$ and ferritin also play crucial roles in this process 
(Connor 1994; Badaracco et al. 2010). In culture, iron deficiency results in loss of viability of oligodendrocyte precursors (Todorich et al. 2011). As may be expected in such a high iron environment, OPCs are very sensitive to oxidation and to the depletion of antioxidants such as glutathione, even more so than mature oligodendrocytes (Back et al. 1998; French et al. 2009). The survival and maturation of OPCs may be especially vulnerable to cigarette smoke - even passive smoking (Sundström et al. 2008). This would imply that these cells would need antioxidant protection during patient relapses, when there is an increased concentration of inflammatory mediators and reactive oxygen species (ROS).

\section{Iron and microglia}

Microglia have three functions with regard to oligodendrocytes: (1) they provide soluble survival factors to them, including iron, under normal conditions (Zhang et al. 2006), (2) they clear away dysfunctional oligodendrocytes and myelin by phagocytosis (Gray et al. 2008), and (3) they assist in remyelination (Matsushima and Morell 2001). During brain development, microglia release iron bound to $\mathrm{Tf}$ to OPCs for a limited time as a trophic factor, but as the OPCs mature into oligodendrocytes there is a down-regulation of transferrin receptors (TfR). The main iron transfer method for mature oligodendrocytes is through $\mathrm{H}$-ferritin, which accumulates in microglia in the vicinity of oligodendrocytes when they start to produce myelin (Todorich et al. 2011). The $\mathrm{H}$-ferritin iron uptake system is unique to oligodendrocytes, since neurons and other cells use the TfR-Tf system to aquire iron. This is consistent with the fact that oligodendrocytes need higher amounts of iron - ferritin can supply more iron to oligodendrocytes than Tf, which transports 2 iron atoms only (Hulet et al. 1999). A transport mechanism for $\mathrm{H}$-ferritin has also been identified on brain microvasculature (Fisher et al. 2007).

\section{Iron deposits in the brain}

Examining putative brain iron content in healthy subjects and in patients with MS using sophisticated imaging technology is a subject of ongoing research (Haacke et al. 2009;2010; Khalil et al. 2009; Ceccarelli et al. 2009); however, these novel techniques have not been considered for diagnostic purposes since they are not yet standardised (Poloni et al. 2011). The iron measured includes hemoglobin in blood vessels, ferritin in brain parenchyma and hemosiderin as iron deposits, as well as iron in MS lesions and amyloid plaques. Iron may vary with respect to age, brain region, hypertension, as well as microbleeds (Rodrigue et al. 2011). Adams (1988) found that the iron deposition in MS reflected damage to vessel walls and "old" hemorrhages in the vicinity of plaques, and that the incidence of hemosiderin deposition in MS was 30\% compared to $6 \%$ in non-MS cases; furthermore, he suggested that inflammation in vessel walls might be exacerbated by surges in intracranial venous pressure. Haacke et al. (2010) found that increased iron content in MS basal ganglia and thalamus formed a particular pattern of iron deposition in the medial venous drainage system at the confluence of the veins draining these structures. Zamboni (2006) postulated that iron mobilised from such deposits may enter the brain parenchyma and become the source of damage to neurons, thereby promoting disability progression. Worthington et al. (2010) investigated this hypothesis, reasoning that if iron from haemolysed erythrocytes were released into brain parenchyma, it should be reflected by increased ferritin in the CSF. Ferritin is one of the pivotal antioxidant defenses in the brain, providing protection against labile iron. Their results showed that CSF ferritin levels in patients with RRMS and PPMS were essentially normal, largely remaining within the range of less than $12 \mathrm{ng} / \mathrm{ml}$. Unexpectedly, in SPMS a relative increase of the concentration of CSF ferritin from baseline to follow-up was related to the degree of improvement of lower limb function and improvement of the T1 lesion volume on MRI. The authors speculated that ferritin in these patients may reflect a physiologic reaction promoting remyelination (Worthington et al. 2010). Furthermore, there was no correlation of baseline CSF ferritin levels with the baseline EDSS, and no significant increase of CSF ferritin levels over a 3-year follow-up period, arguing against a gradual build-up of iron.

If deposition of iron in the brain in MS were an important predictor of morbidity, it should correlate with disability. However, a study by Ceccarelli et al. (2009) demonstrated that patients with benign MS and SPMS had similar amounts of iron deposition, suggesting that disability in MS may be related to factors other than iron deposition. Furthermore, if the procedure of relieving venous congestion as proposed by Zamboni (2006) is indeed followed by rapid relief of MS symptoms, it is unlikely to be related to immediate resolution of iron deposits. The fact that clinically benign MS may occur despite large lesion loads on MRI has been described as paradoxical (Strasser-Fuchs et al. 2008); the 'clinical-radiologic paradox' (Poloni et al. 2011).

Iron deposition has also been described in other brain disorders, such as Parkinson's disease (PD) (Elolf et al. 2007; Michaeli et al. 2007). However, investigations of systemic iron concentrations revealed significantly lower blood iron parameters in PD compared to controls (Logroscino et al. 1997; Marder et al. 1998). These authors hypothesised that a shift of iron from the blood compartment to the brain compartment had taken place due to iron 
dysregulation, leading to iron deposition due to excess iron in the brain. They furthermore hypothesised that iron removal by blood donation should limit the negative effects of excess iron and lower the risk of PD (Logroscino et al. 2006). To test this hypothesis, they studied 38,411 participants in the Health Professionals Follow-Up Study who provided details of blood donation. The results were unexpected: although the number of blood donations was inversely related to the ferritin levels, no association was found between the number of blood donations and risk of PD ( $P$ for trend $=0.6)$; however, the risk of PD was higher among men who had reported recent multiple blood donations $(P$ for trend $=0.05)$. Since dopamine synthesis is dependent on iron availability, iron restriction may cause apoptotic demise of dopaminergic neurons in susceptible individuals (Levenson et al. 2004). Furthermore, Marder et al. (1998) observed that lower serum iron concentrations and elevated serum Tf receptors were associated with mortality in patients with PD, but not in controls. These unexpected findings may emphasise the essential requirement of iron for the viability of dopaminergic neurons and that the iron deposition in PD may represent cells that suffered damage paradoxically as a result of inadequate iron availability. This may confirm that additional biochemical factors need to be considered when iron restriction or removal by chelation is advocated (Levenson et al. 2004).

\section{The role of iron in the cellular antioxidant system}

Contrary to the belief that iron is harmful and invariably causes oxidative damage, it may paradoxically represent the key component of the entire antioxidant protection system of the oligodendrocyte, since:

(1) Iron is required for the production of ATP, which is essential for the synthesis of NADPH, the reducing power of the cell. NADPH constantly regenerates the reduced form of glutathione, an important component of oligodendrocyte antioxidant protection. NADPH is produced in oligodendrocytes by the pentose phosphate pathway (PPP) (Todorich et al. 2009). The phosphate group of glucose-6-phosphate, the substrate of the rate limiting enzyme of the PPP (glucose-6-phosphate dehydrogenase), comes from ATP (Voet and Voet, 2004). A genetic variation in hexose-6-phosphate dehydrogenase, which generates NADPH in the endoplasmic reticulum, was found to be associated with MS (Alcina et al. 2010).

(2) More directly, iron forms part of the structure of catalase, an antioxidant enzyme that converts $\mathrm{H}_{2} \mathrm{O}_{2}$ to water and oxygen (Kirkman and Gaetani 2007). NADPH is responsible for maintaining the active form of the 4 haem groups of catalase.
(3) NADPH and iron are also involved in anabolic reactions. NADPH provides the reducing power for the synthesis of lipids such as cholesterol, which are produced by oligodendrocytes for their own membranes (Morell and Jurevics 1996; Todorich et al. 2009). The synthesis of one cholesterol molecule requires 19 reductions by NADPH (Voet and Voet 2004). To make one molecule of palmitic acid, a component of sphingomyelin, requires 12 NADPH reductions. Haem cofactors in cytochrome P450 enzymes catalyse the essential hydroxylation reactions in the synthesis of cholesterol. Furthermore, the hydroxylations that produce $1,25(\mathrm{OH})_{2} \mathrm{D}_{3}$ (active vitamin D) from cholesterol are carried out by a cytochrome P450 enzyme called CYP27B1. A significant association of a genetic variant of CYP27B1 with MS has been found (Sundqvist et al. 2010; Ramagopalan et al. 2011). Oligodendrocytes express vitamin $D_{3}$ receptors and respond to $1,25(\mathrm{OH})_{2} \mathrm{D}_{3}$ (Baas et al. 2000). Some cells can produce antibacterial proteins to overcome infections by synthesizing $1,25(\mathrm{OH})_{2} \mathrm{D}_{3}$ (Kamen and Tangpricha 2010), but they will only be able to do so in the presence of sufficient iron, because the relevant cytochrome P450 enzyme has to be synthesized as well, and each enzyme would need a haem group.

\section{Iron deficiency in MS}

Iron deficiency may contribute to the finding that more females than males are diagnosed with MS (Warren et al. 2008). In females, deficiencies of iron availability to the brain may arise by (1) iron use elsewhere in the body, such as before and during menstruation when iron is re-routed to synthesise erythrocytes, and (2) iron loss during pregnancy and childbirth, which may amount to $20-25 \%$ of maternal iron (de Jong et al. 1990). Relapses are often experienced after childbirth, leading some clinicians to advise women with MS not to have children. In an ongoing study we found that relapses are prevented when women take iron supplements (together with other nutrients) during and after pregnancy (results to be published elsewhere). Furthermore, fatigue is a frequent symptom of MS. Some patients present at diagnosis with such low iron levels that intravenous iron may be required, and if given timeously, demyelination may be reversed and disease progression stopped (Kotze et al. 2010). In our study population two females and a male were diagnosed with MS after blood donation. The male reported frequent multiple blood donations. Although his hemoglobin was normal $(12.1 \mathrm{~g} / \mathrm{dl})$, all his other iron measures were extremely low: his serum iron fell to $1.9 \mu \mathrm{mol} / 1$ (range $10.0-30.0)$, his Tf saturation to $2 \%(20-50)$ and his ferritin to $7.6 \mu \mathrm{g} / \mathrm{l}(22-322)$. He recovered rapidly following iron supplementation and has remained in remission, an indication 
of the importance of taking a detailed history at diagnosis and doing biochemical measurements (Haug PD and van Rensburg SJ, unpublished case studies). Notably, Newman (2006) has suggested that blood donation may cause harm to menstruating females, including neurological sequelae, and the REDS-II Donor Iron Status Evaluation (RISE) study has issued recommendations for iron supplementation in blood donors (Cable et al. 2011).

The link between iron deficiency and obesity may also be of relevance in MS, since obesity may be a risk factor for MS in adolescent females (Munger et al. 2009). Iron deficiency in obese women has been ascribed to chronic, low grade inflammation (Cepeda-Lopez et al. 2011).

\section{Other requirements of oligodendrocytes}

Iron, vitamin B12 and folate influence the absorption of one another. Myelination grinds to a halt if the folate-vitamin B12 pathway is blocked by mutations or by deficiencies of the substrates (Surtees et al. 1991; Ilniczky et al. 2002; Selzer et al. 2003), because folate-vitamin B12 metabolism is required for methylation of DNA, lipids (such as the production of phosphatidyl choline from phosphatidyl ethanolamine) and proteins, such as myelin basic protein (Baldwin and Carnegie 1971). The oligodendrocyte also requires amino acids for protein synthesis and for protection against retrovirus HERV's envelope protein ERV, which blocks amino acid uptake receptors (Perron and Lang 2010). Glycine and glutathione (glutamate-cysteine-glycine) are used in cellular detoxification reactions. Oligodendrocytes also need antioxidants and essential fatty acids for synthesising lipids (Nordvik et al. 2000). Sufficient vitamin D is protective against MS diagnosis (Ascherio et al. 2010) and is associated with improved clinical and MRI outcomes (Weinstock-Guttman et al. 2011), although the biochemical mechanism has not yet been elucidated. Since the life of oligodendrocytes depends on adequate blood flow for provision of nutrients and removal of toxic waste products, it is evident that all components of the cerebral vascular system need to function optimally.

\section{Genetics of iron metabolism in MS}

The role of iron in MS will only be fully elucidated once more information becomes available about the effects of genetic variations regulating iron metabolism, including those leading to iron deficiency. The regulation of iron uptake and transport is extremely complex and involves many different biochemical factors, some of which are unexpectedly involved.

The genetics of iron metabolism in MS has to date largely focused on the analysis of the SLC11A1 (NRAMP1) and
$H F E$ genes involved in iron transport and absorption (Table 2). Insights gained from studies performed in a genetically homogeneous South African population paved the way to a better understanding of the close relationship between iron absorption and immune function in MS (Kotze et al. 2001; 2003; 2006). The statistically significant association observed between MS and a functional promoter polymorphism in the SLC11A1 gene, supports the notion that iron trapping in macrophages upon infection may be detrimental in a subgroup of MS patients that are iron deficient (Kotze et al. 2003; van Rensburg et al. 2006). The HFE gene may be in linkage disequilibrium with an MS susceptibility allele in the HLA complex on chromosome 6 (Rubio et al. 2004; Kotze et al. 2006). Lack of clinical manifestation of hereditary hemochromatosis $(\mathrm{HH})$ without any signs of organ damage in two South African sisters with MS found to be homozygous for the $\mathrm{C} 282 \mathrm{Y}$ mutation in the HFE gene, further substantiates the role of iron dysregulation in the aetiology of MS (Kotze et al. 2006). Notably, iron deficiency anaemia was reported in one of these patients during her child-bearing years. Iron regulation by hepcidin may account for these contradictory findings.

Hepcidin is an iron-regulatory hormone which together with its receptor ferroportin, controls the dietary absorption, storage and tissue distribution of iron (Ganz 2011). Infection and inflammation (strongly implicated in MS) rapidly increases hepcidin synthesis and leads to decreased iron absorption and retention of iron in macrophages. Although genetic variation affecting the hepcidin-ferroportin axis is a major cause of iron overload, the presence of inflammation could lead to iron-restricted anaemia. Differential expression of hepcidin and ferroportin during infection and inflammation links iron metabolism to host defence and decreases iron availability to invading pathogens. This response also restricts the iron supply to erythropoietic precursors, thereby contributing to anaemia of chronic disease (the anaemia associated with infections and inflammatory disorders). The resultant hypoferraemia limits iron availability to microorganisms but may therefore also lead to cellular iron deficiency in MS during inflammatory episodes. Recently, it was discovered that the TMPRSS6 gene encodes a protein that negatively regulates hepcidin expression ( $\mathrm{Cau}$ et al. 2010). Some polymorphisms or sporadic mutations in this gene cause hepcidin overexpression and iron deficiency anaemia (Beutler et al. 2010).

An important development in the field of genetics in MS has been the use of a novel approach to investigate the effects of genetic variation on clinical outcome (Ramagopalan et al. 2008a). When comparisons are made of MS cases selected from opposite extremes of the disease outcome spectrum, i.e. the prognostic best 5\% (benign MS) and worst $5 \%$ (malignant MS) as assessed by the EDSS, the 
Table 2 Summary of susceptibility and disease outcome studies performed in MS patients and controls in relation to genetic variation in the ironrelated SLC11A1 and HFE genes

\begin{tabular}{|c|c|c|c|c|}
\hline Gene & Country & Study size & Association & References \\
\hline \multirow[t]{4}{*}{$S L C 11 A 1$} & South Africa & $\begin{array}{l}104 \text { MS patients, } 522 \text { controls including } 32 \\
\text { parental alleles as family-based controls }\end{array}$ & Yes & Kotze et al. 2001 \\
\hline & Spain & 195 MS patients, 125 controls & No & Comabella et al. 2004 \\
\hline & Sardinia & $66 \mathrm{MS}$ patients, 60 controls & Yes & Gazouli et al. 2008 \\
\hline & Turkey & 100 MS patients, 100 controls & No & Ates et al. 2010 \\
\hline \multirow[t]{5}{*}{$H F E$} & Tasmania & $\begin{array}{l}166 \text { MS families, } 489 \text { MS patients, } \\
104 \text { control families }\end{array}$ & $\begin{array}{l}\text { No clinical, despite } 3 \text {-fold increase } \\
\text { of } \mathrm{C} 282 \mathrm{Y} \text { in MS }\end{array}$ & Rubio et al. 2004 \\
\hline & Slovenia & 314 MS patients, 400 controls & $\begin{array}{l}\text { No, although earlier onset of MS symptoms } \\
\text { noted in } \mathrm{C} 282 \mathrm{Y} \text { carriers }\end{array}$ & Ristic et al. 2005 \\
\hline & South Africa & 118 MS patients, 102 controls & $\begin{array}{l}\text { No, although two sisters with MS } \\
\text { (without } \mathrm{HH} \text { ) were } \mathrm{C} 282 \mathrm{Y}++\end{array}$ & Kotze et al. 2006 \\
\hline & UK & 112 benign and 51 malignant MS patients & No & $\begin{array}{l}\text { Ramagopalan et al. } \\
\text { 2008a, b }\end{array}$ \\
\hline & Portugal & 373 MS patients & $\begin{array}{l}\text { No, although MS patients with mutation } \\
\text { C282Y had a worse prognosis }\end{array}$ & Bettencourt et al. 2011 \\
\hline
\end{tabular}

$H H$ hereditary hemochromatosis

effective sample size increases about 40 times, and provides more than $99 \%$ power to detect a quantitative trait locus contributing to only $2 \%$ of the phenotypic variance (DeLuca et al. 2007). Using this method, no evidence was found that mutations in $H F E$ have any effect on clinical outcome in MS (Ramagopalan et al. 2008a). The likelihood that a diagnosis of MS affects the clinical manifestation of HH could however not be excluded (Kotze et al. 2006). A further 45 different genes, reviewed by Ramagopalan et al. (2008b), both MHC and non-MHC-related, had no effect on clinical outcome: the genes selected were related to immune function, neurobiology, autoimmunity and myelin proteins. Interestingly, the $-308 \mathrm{~A}$ allelic variant in the promotor region of $T N F-\alpha$ gene significantly decreased the risk of MS (Yang et al. 2010), while in another study this variant was shown to increase iron uptake (Krayenbuehl et al. 2006). These subtle effects of iron regulation in MS should be further investigated.

\section{The role of Human Leukocyte Antigen (HLA) in MS}

Risk for MS diagnosis has previously been attributed to specific haplotypes of the MHC II immune system (HLA in humans) which may increase MS risk with an odds ratio of more than 30 (Ramagopalan and Ebers, 2009). Whilst MS susceptibility is linked to $H L A-D R B 1 * 1501$, protection against disease progression may be afforded by $H L A$ $D R B 1^{*} 01$ (DeLuca et al. 2007). The classical role of MHC II (e.g. in EAE) is to activate T cells by antigen presentation. However, an in vivo cuprizone model in mice (Hiremath et al. 2008; Matsushima and Morell 2001) revealed that MHC II may be involved in demyelination independently of $\mathrm{T}$ cells. Cuprizone is a copper chelator which exclusively affects oligodendrocytes causing mitochondrial injury, downregulation of mRNA and subsequent apoptosis. This occurs in the absence of T cells, since the BBB stays intact. It was assumed (Matsushima and Morell 2001) that the susceptibility of oligodendrocytes to cuprizone was due to their extreme dependence on energy production for maintenance of the vast myelin sheath, a situation that parallels iron deficiency as discussed above.

MHC II molecules are expressed on activated microglia. In the cuprizone model, microglia are activated not by antigen presentation but through cell signaling (Hiremath et al. 2008). Activated microglia produce TNF- $\alpha$, IL-1 $\beta$ and $\mathrm{NO}$ which exacerbate the process of demyelination. Interestingly, microglia of mice in which MHC II was absent $\left(\mathrm{I}-\mathrm{A}_{\beta}{ }^{-/}\right)$showed reduced activation and cytokine production, while other mice with truncated $\beta$ chains $\left(\mathrm{I}-\mathrm{A}_{\beta}{ }^{\mathrm{tr}}\right.$ ) showed similar results, indicating that the cytoplasmic tail of the MHC II molecule was necessary for microglial activation, cell signaling and cytokine production. The mutant mice exhibited significantly reduced demyelination at week 3 , however after 5 weeks of cuprizone treatment the amount of demyelination was similar between wild type and mutant mice. If mice were transferred to a cuprizone-free diet within 6 weeks, full remyelination occurred (Matsushima and Morell 2001), demonstrating that an energy deficiency in oligodendrocytes can initiate demyelination and microglial activation. These intriguing results tempt us to speculate that different genetic variants of HLA II may contribute to the underlying genetic predisposition to MS (Fig. 1) and affect MS outcome differentially due to the 
effects of these alleles on microglial activation - some genetic variants may cause over-activation or an inability of microglia to terminate their activation when needed ("water damage caused by the fire brigade"). We furthermore hypothesise that if oligodendrocytes and OPCs were protected against apoptosis, microglial activation would be prevented, leading to prolonged remission in MS (Fig. 1). Such an approach would help to shift the focus in MS towards preventative care (Collins 2010). However, it also has implications for MS treatment. Microglial activation is attenuated by cortisone (Kaur et al. 1994), CD200 (Koning et al. 2009), antipsychotic drugs (Doorduin et al. 2009), polyunsaturated fatty acids (Liuzzi et al. 2007) and vitamin D (Lefebvre d'Hellencourt et al. 2003). Microglia express vitamin D receptors, and are able to synthesize $1,25(\mathrm{OH})_{2} \mathrm{D}_{3}$ (Neveu et al. 1994); again, iron would be required for the relevant cytochrome P450 enzyme.

It would be of interest to establish whether HLA alleles affect the role of microglia in remyelination, whereby they deliver insulin-like growth factor-1 (IGF-1) (Matsushima and Morell 2001), TNF- $\alpha$ (Arnett et al. 2001) and iron (Zhang et al. 2006) to oligodendrocyte precursors.

\section{Randomised clinical trials for iron in MS?}

Medical regulations dictate that treatment of MS patients should be guided by Evidence-based Medicine (EBM), i.e. by the highest available standard of evidence obtained from randomised clinical trials (RCTs). However, Caplan (2011) argues that the effective clinical neurologist should ask the question: "How well does the evidence from trials apply to the care of individual patients?" For most clinicians, the requirement for iron (or not) in MS should be relatively simple to investigate by doing RCTs. Unfortunately, this method may probably not provide the answer. Although iron chelation therapy has been promoted as a potential treatment, the trial by Lynch et al. (2000), in which one patient improved while others worsened, illustrates the point that iron requirements differ, and raises the question of whether it is useful to treat all MS patients according to the one-size-should-fit-all approach of RCTs, that determines similar intervention in all patients because a significant number of patients (but not all) responded during the trial. Steiner and Mosberg-Galili (2010) have questioned the reliability of even testing DMTs with RCTs in MS, since it is not known whether MS is a single disease or rather a group of various disease entities. When such an extremely heterogeneous population is recruited into RCTs, results are difficult to interpret. Steiner and Wirguin (2000) have argued that "the almost identical results of clinical trials using different agents, and their inability to go beyond the $33 \%$ line, raise the possibility that the entire observed benefit is only a placebo effect, and that the significant deviation from the true placebo might be the outcome of partial unblinding of patients by the side-effects". The failure of DMTs to stop disability progression contributes to this view (Filippini et al. 2008). RCTs of iron in an unselected population of MS patients cannot be informative, since iron deficiency does not occur in all patients with MS; if iron deficiency is identified in a particular patient, it would be unethical not to prescribe iron. The same is true for haemochromatosis: even though HFE screening is one of the most common genetic tests requested in general practice, no RCT has yet been done to determine treatment strategy, since excessive iron levels already necessitate clinical intervention. Furthermore, supplying the oligodendrocyte with only one essential element when it needs multiple different nutrients would be like inundating a car factory with rubber. Once enough wheels have been manufactured, more rubber will only clog the system. Future RCTs for MS should take cognizance of the existence of different MS subgroups that may respond differently to different intervention modalities.

\section{The advantages of individualised treatment}

In the light of the heterogeneity of MS (Steiner and Mosberg-Galili 2010) and the extreme variability of disease outcome (DeLuca et al. 2007), it has been suggested that individualised treatment of MS patients would have more success (Wekerle and Hohlfeld 2010), but this should extend further than deciding which drug to prescribe. Rather than waiting for autoimmune biomarkers to be found (Hohlfeld 2010), biochemical biomarkers (such as iron, vitamin B12 and vitamin D) are already available and should be utilised to alleviate deficiencies and to ensure that blood levels remain within the optimal range for myelination. The symptoms of vitamin B12 deficiency may mimic those of MS (Ungley and Campbell 1951); misdiagnosis of MS with consequent disability is particularly tragic in light of the fact that vitamin B12 deficiency is an easily diagnosed and treatable disorder. Objective evidence for improvement is provided by doing the EDSS; differences can already be seen over 3-6 months and can be confirmed over longer periods (Nordvik et al. 2000; van Rensburg et al. 2006). Since MS patients differ it should never be assumed that disease progression is inevitable. Do all health professionals take note of the evidence for MS risk factors such as smoking and vitamin D deficiency? Since it is assumed that patients will inevitably experience disease progression, smoking is sometimes tolerated on the basis of "it is their only remaining pleasure", instead of actively working with each patient to minimize their risk. Furthermore, pharmacogenetics may provide useful information, since 
immunosuppressive drugs such as azathioprine and methotrexate will have adverse effects in patients with mutations in the methylation pathway. Increased relapse rates have been recorded for patients on some of these drugs (Confavreux et al. 2000).

In the clinical setting, the needs of clinicians and patients differ. Patients need encouragement instead of being informed at diagnosis that they need to prepare themselves for inevitable disability. Many patients lose hope at that point, some even dropping out of the workplace, while the truth is that rehabilitation is possible (Fink et al. 2010) and that up to a third of patients may have a benign disease course (Pittock et al. 2004). Does the fact that benign patients have minimal disability after more than 20 years indicate that these patients are doing something right, possibly protecting their oligodendrocytes against cell death? Research should be encouraged to investigate whether the favorable outcome of these patients is related to genetics, or to environmental factors, or both (Mastorodemos et al. 2010). A recent study reported that sequencing the genome of monozygotic twins discordant for MS provided no evidence that the DNA of the twins differed in DNA sequence, DNA methylation or gene expression (Baranzini et al. 2010). Among our own patients, investigation of a similar monozygotic pair of twins discordant for MS revealed that the unaffected twin does not smoke, while the twin with MS smokes and has low blood levels of essential biochemicals, due to the fact that she was under the false impression that nutrient supplementation would "activate her immune system". Since it may be difficult to defend autoimmunity in MS at this time (Rodriguez 2009; Steiner and Mosberg-Galili 2010), it may need to be reconsidered whether it is reasonable to motivate patients to administer DMTs if they have fewer exacerbations when they abstain (Hancock et al. 2011).

\section{Conclusion}

The conundrum of iron in MS may be solved when it is approached from an individualised point of view. The heterogeneity of the disease warrants the following question: What factors are present that may impact on demyelination and how should they be alleviated in individual patients? Adequate research already exists on essential requirements for oligodendrocyte survival and remyelination. The value of biochemical testing performed in conjunction with a medical, lifestyle and genetic assessment when appropriate (Pathology Supported Genetic Testing), should not be under-estimated. Further studies are essential to establish the validity of these concepts.
Acknowledgements The authors gratefully acknowledge grant support from the National Health Laboratory Service (NHLS), the University of Stellenbosch and the Medical Research Council of South Africa. The following colleagues are thanked for overseeing the MS project and for collaboration and discussions: Profs Rajiv Erasmus, Johann Schneider and Johan Schoeman, Drs Mathias de Fleuriot and Frans Cronje, and Sr Treska Botha.

Conflict of interest Prof MJ Kotze is a director and shareholder of Gknowmix (Pty) Ltd. that developed a database tool for conversion of research and innovation under the auspices of the Innovation Centre of the South African Medical Research Council. The other authors declare that they have no conflict of interest.

\section{References}

Adams CW (1988) Perivascular iron deposition and other vascular damage in multiple sclerosis. J Neurol Neurosurg Psychiatry $51: 260-265$

Alcina A, Ramagopalan SV, Fernández O, Catalá-Rabasa A, Fedetz M, Ndagire D, Leyva L, Arnal C, Delgado C, Lucas M, Izquierdo G, Ebers GC, Matesanz F (2010) Hexose-6-phosphate dehydrogenase: a new risk gene for multiple sclerosis. Eur J Hum Genet 18:618-620

Arnett HA, Mason J, Marino M, Suzuki K, Matsushima GK, Ting JP (2001) TNF alpha promotes proliferation of oligodendrocyte progenitors and remyelination. Nat Neurosci 4:1116-1122

Ascherio A, Munger KL, Simon KC (2010) Vitamin D and multiple sclerosis. Lancet Neurol 9:599-612

Ates O, Kurt S, Bozkurt N, Karaer H (2010) NRAMP1 (SLC11A1) variants: genetic susceptibility to multiple Sclerosis. J Clin Immunol 30:583-586

Axtell RC, Raman C, Steinman L (2011) Interferon- $\beta$ exacerbates Th17mediated inflammatory disease. Trends Immunol 32:272-277

Baas D, Prüfer K, Ittel ME, Kuchler-Bopp S, Labourdette G, Sarliève LL, Brachet P (2000) Rat oligodendrocytes express the vitamin D (3) receptor and respond to 1,25-dihydroxyvitamin $\mathrm{D}(3)$. Glia 31:59-68

Back SA, Gan X, Li Y, Rosenberg PA, Volpe JJ (1998) Maturationdependent vulnerability of oligodendrocytes to oxidative stressinduced death caused by glutathione depletion. J Neurosci 18:6241-6253

Badaracco ME, Siri MV, Pasquini JM (2010) Oligodendrogenesis: the role of iron. Biofactors 36:98-102

Baldwin GS, Carnegie PR (1971) Specific enzymic methylation of an arginine in the experimental allergic encephalomyelitis protein from human myelin. Science 171:579-581

Baranzini SE, Mudge J, van Velkinburgh JC, Khankhanian P, Khrebtukova I, Miller NA, Zhang L, Farmer AD, Bell CJ, Kim RW, May GD, Woodward JE, Caillier SJ, McElroy JP, Gomez R, Pando MJ, Clendenen LE, Ganusova EE, Schilkey FD, Ramaraj T, Khan OA, Huntley JJ, Luo S, Kwok PY, Wu TD, Schroth GP, Oksenberg JR, Hauser SL, Kingsmore SF (2010) Genome, epigenome and RNA sequences of monozygotic twins discordant for multiple sclerosis. Nature 464:1351-1356

Barnett MH, Prineas JW (2004) Relapsing and remitting multiple sclerosis: pathology of the newly forming lesion. Ann Neurol $55: 458-468$

Barnett MH, Henderson AP, Prineas JW (2006) The macrophage in MS: just a scavenger after all? Pathology and pathogenesis of the acute MS lesion. Mult Scler 12:121-132

Behan PO, Chaudhuri A (2010) The sad plight of multiple sclerosis research (low on fact, high on fiction): critical data to support it being a neurocristopathy. Inflammopharmacology 18:265-290 
Bettencourt A, Silva AM, Santos E, Gomes S, Mendonça D, Costa PP, Faustino P, Silva BM (2011) HFE gene polymorphisms and severity in Portuguese patients with multiple sclerosis. Eur J Neurol 18:663-666

Beutler E, Van Geet C, te Loo DM, Gelbart T, Crain K, Truksa J, Lee PL (2010) Polymorphisms and mutations of human TMPRSS6 in iron deficiency anaemia. Blood Cells Mol Dis 44:16-21

Byun E, Caillier SJ, Montalban X, Villoslada $\mathrm{P}$, Fernández $\mathrm{O}$, Brassat D, Comabella M, Wang J, Barcellos LF, Baranzini SE, Oksenberg JR (2008) Genome-wide pharmacogenomic analysis of the response to interferon beta therapy in multiple sclerosis. Arch Neurol 65:337-344

Cable RG, Glynn SA, Kiss JE, Mast AE, Steele WR, Murphy EL, Wright DJ, Sacher RA, Gottschall JL, Vij V, Simon TL; for the NHLBI Retrovirus Epidemiology Donor Study-II (REDS-II) (2011) Iron deficiency in blood donors: analysis of enrollment data from the REDS-II Donor Iron Status Evaluation (RISE) study. Transfusion 51:511-522

Cammer W (2002) Protection of cultured oligodendrocytes against tumor necrosis factor-alpha by the antioxidants coenzyme Q(10) and N-acetyl cysteine. Brain Res Bull 58:587-592

Cau M, Melis MA, Congiu R, Galanello R (2010) Iron-deficiency anaemia secondary to mutations in genes controlling hepcidin. Expert Rev Hematol 3:205-216

Caplan LR (2011) Evidence and the effective clinical neurologist: the 2009 H. Houston Merritt Lecture. Arch Neurol 68:1252-1256

Ceccarelli A, Filippi M, Neema M, Arora A, Valsasina P, Rocca MA, Healy BC, Bakshi R (2009) T2 hypointensity in the deep gray matter of patients with benign multiple sclerosis. Mult Scler 15:678-686

Cepeda-Lopez AC, Osendarp SJ, Melse-Boonstra A, Aeberli I, Gonzalez-Salazar F, Feskens E, Villalpando S, Zimmermann MB (2011) Sharply higher rates of iron deficiency in obese Mexican women and children are predicted by obesity-related inflammation rather than by differences in dietary iron intake. Am J Clin Nutr 93:975-983

Collins FS (2010) The language of life. DNA and the revolution in personalized medicine. Harper Perennial, New York

Comabella M, Altet L, Peris F, Villoslada P, Sánchez A, Montalban X (2004) Genetic analysis of SLC11A1 polymorphisms in multiple sclerosis patients. Mult Scler 10:618-620

Confavreux C, Vukusic S, Moreau T, Adeleine P (2000) Relapses and progression of disability in multiple sclerosis. N Engl J Med 343:1430-1438

Connor JR (1994) Iron acquisition and expression of iron regulatory proteins in the developing brain: manipulation by ethanol exposure, iron deprivation and cellular dysfunction. Dev Neurosci 16:233-247

Connor JR, Menzies SL (1996) Relationship of iron to oligodendrocytes and myelination. Glia 17:83-93

Corthals AP (2011) Multiple sclerosis is not a disease of the immune system. The Q Rev Biol 86:287-321

Dale JC, Burritt MF, Zinsmeister AR (2002) Diurnal variation of serum iron, iron-binding capacity, transferrin saturation, and ferritin levels. Am J Clin Pathol 117:802-808

de Jong G, van Dijk JP, van Eijk HG (1990) The biology of transferrin. Clin Chim Acta 190:1-46

DeLuca GC, Ramagopalan SV, Herrera BM, Dyment DA, Lincoln MR, Montpetit A, Pugliatti M, Barnardo MC, Risch NJ, Sadovnick AD, Chao M, Sotgiu S, Hudson TJ, Ebers GC (2007) An extremes of outcome strategy provides evidence that multiple sclerosis severity is determined by alleles at the HLA-DRB1 locus. Proc Natl Acad Sci U S A 104:20896-20901

Doorduin J, de Vries EF, Willemsen AT, de Groot JC, Dierckx RA, Klein HC (2009) Neuroinflammation in schizophrenia-related psychosis: a PET study. J Nucl Med 50:1801-1807

Elolf E, Bockermann V, Gringel T, Knauth M, Dechent P, Helms G (2007) Improved visibility of the subthalamic nucleus on high-resolution stereotactic MR imaging by added susceptibility (T2*) contrast using multiple gradient echoes. AJNR Am J Neuroradiol 28:1093-1094

Fassl S, Leisser C, Huettenbrenner S, Maier S, Rosenberger G, Strasser S, Grusch M, Fuhrmann G, Leuhuber K, Polgar D, Stani J, Tichy B, Nowotny C, Krupitza G (2003) Transferrin ensures survival of ovarian carcinoma cells when apoptosis is induced by TNFalpha, FasL, TRAIL, or Myc. Oncogene 22:8343-8355

Filippi M, Rocca MA, Barkhof F, Bakshi R, Fazekas F, Khan O, Pelletier D, Rovira A, Simon J (2011) Multiple sclerosis and chronic cerebrospinal venous insufficiency: the neuroimaging perspective. AJNR Am J Neuroradiol 32:424-427

Filippini G, Moja L, Liberati A, Gensini GF, Gusinu R, Conti AA (2008) When drug companies select what they want to publish patients are denied relevant therapeutic information. Intern Emerg Med 3:255-257

Fink F, Rischkau E, Butt M, Klein J, Eling P, Hildebrandt H (2010) Efficacy of an executive function intervention programme in MS: a placebo-controlled and pseudo-randomised trial. Mult Scler 16:1148-1151

Fisher J, Devraj K, Ingram J, Slagle-Webb B, Madhankumar AB, Liu X, Klinger M, Simpson IA, Connor JR (2007) Ferritin: a novel mechanism for delivery of iron to the brain and other organs. Am J Physiol Cell Physiol 293:C641-C649

French HM, Reid M, Mamontov P, Simmons RA, Grinspan JB (2009) Oxidative stress disrupts oligodendrocyte maturation. J Neurosci Res 87:3076-87

Ganz T (2011) Hepcidin and iron regulation, 10 years later. Blood 117:4425-4433

Gazouli M, Sechi L, Paccagnini D, Sotgiu S, Arru G, Nasioulas G, Vassilopoulos D (2008) NRAMP1 polymorphism and viral factors in Sardinian multiple sclerosis patients. Can J Neurol Sci 35:491-494

Gerber MR, Connor JR (1989) Do oligodendrocytes mediate iron regulation in the human brain? Ann Neurol 26:95-98

Grant SM, Wiesinger JA, Beard JL, Cantorna MT (2003) Iron-deficient mice fail to develop autoimmune encephalomyelitis. J Nutr 133:2635-2638

Gray E, Thomas TL, Betmouni S, Scolding N, Love S (2008) Elevated activity and microglial expression of myeloperoxidase in demyelinated cerebral cortex in multiple sclerosis. Brain Pathol 18:86-95

Haacke EM, Makki M, Ge Y, Maheshwari M, Sehgal V, Hu J, Selvan M, Wu Z, Latif Z, Xuan Y, Khan O, Garbern J, Grossman RI (2009) Characterizing iron deposition in multiple sclerosis lesions using susceptibility weighted imaging. J Magn Reson Imaging 29:537-544

Haacke EM, Garbern J, Miao Y, Habib C, Liu M (2010) Iron stores and cerebral veins in MS studied by susceptibility weighted imaging. Int Angiol 29:149-157

Hancock LM, Bruce JM, Lynch SG (2011) Exacerbation history is associated with medication and appointment adherence in MS. J Behav Med 34:330-338

Hiremath MM, Chen VS, Suzuki K, Ting JP, Matsushima GK (2008) MHC class II exacerbates demyelination in vivo independently of T cells. J Neuroimmunol 203:23-32

Hohlfeld R (2010) 'Gimme five': future challenges in multiple sclerosis. ECTRIMS Lecture 2009. Mult Scler 16:3-14

Healy BC, Ali EN, Guttmann CR, Chitnis T, Glanz BI, Buckle G, Houtchens M, Stazzone L, Moodie J, Berger AM, Duan Y, Bakshi R, Khoury S, Weiner H, Ascherio A (2009) Smoking and disease progression in multiple sclerosis. Arch Neurol 66:858-864

Hulet SW, Powers S, Connor JR (1999) Distribution of transferrin and ferritin binding in normal and multiple sclerotic human brains. J Neurol Sci 165:48-55 
Ilniczky S, Jelencsik I, Kenéz J, Szirmai I (2002) MR findings in subacute combined degeneration of the spinal cord caused by nitrous oxide anaesthesia - two cases. Eur J Neurol 9:101104

Jana A, Pahan K (2007) Oxidative stress kills human primary oligodendrocytes via neutral sphingomyelinase: implications for multiple sclerosis. J Neuroimmune Pharmacol 2:184-193

Kamen DL, Tangpricha V (2010) Vitamin D and molecular actions on the immune system: modulation of innate and autoimmunity. J Mol Med (Berl) 88:441-450

Kaur C, Wu CH, Wen CY, Ling EA (1994) The effects of subcutaneous injections of glucocorticoids on amoeboid microglia in postnatal rats. Arch Histol Cytol 57:449-459

Kell DB (2009) Iron behaving badly: inappropriate iron chelation as a major contributor to the aaetiology of vascular and other progressive inflammatory and degenerative diseases. BMC Med Genomics 2:2

Khalil M, Enzinger C, Langkammer C, Tscherner M, Wallner-Blazek M, Jehna M, Ropele S, Fuchs S, Fazekas F (2009) Quantitative assessment of brain iron by $\mathrm{R}(2) *$ relaxometry in patients with clinically isolated syndrome and relapsing-remitting multiple sclerosis. Mult Scler 15:1048-1054

Kim YS, Kim SU (1991) Oligodendroglial cell death induced by oxygen radicals and its protection by catalase. J Neurosci Res 29:100-106

Kimball S, Vieth R, Dosch HM, Bar-Or A, Cheung R, Gagne D, O'Connor P, D'Souza C, Ursell M, Burton JM (2011) Cholecalciferol plus calcium suppresses abnormal PBMC reactivity in patients with multiple sclerosis. J Clin Endocrinol Metab 96:2826-2834

Kirkman HN, Gaetani GF (2007) Mammalian catalase: a venerable enzyme with new mysteries. Trends Biochem Sci 32:44-50

Koc M, Nad'ová Z, Truksa J, Ehrlichová M, Kovár J (2005) Iron deprivation induces apoptosis via mitochondrial changes related to Bax translocation. Apoptosis 10:381-393

Koning N, Uitdehaag BM, Huitinga I, Hoek RM (2009) Restoring immune suppression in the multiple sclerosis brain. Prog Neurobiol 89:359-368

Kotze MJ, Rooney RN (1997) Hereditary biochemical multiple sclerosis: a new subtype of multiple sclerosis characterized by porphyria-like symptoms? Am J Hum Genet 61(Suppl): A 255

Kotze MJ, de Villiers JN, Rooney RN, Grobbelaar JJ, Mansvelt EP, Bouwens CS, Carr J, Stander I, du Plessis L (2001) Analysis of the NRAMP1 gene implicated in iron transport: association with multiple sclerosis and age effects. Blood Cells Mol Dis 27:44-53

Kotze MJ, de Villiers JNP, Zaahl MG, Robson K (2003) The role of iron metabolism in multiple sclerosis. In: Zatta P (ed) Metal ions and neurodegenerative disorders. World Sci, Singapore, London, pp 399-414

Kotze MJ, de Villiers JN, Warnich L, Schmidt S, Carr J, Mansvelt E, Fourie E, van Rensburg SJ (2006) Lack of clinical manifestation of hereditary haemochromatosis in South African patients with multiple sclerosis. Metab Brain Dis 21:109-120

Kotze MJ, van Rensburg SJ, Rooney R, Haug PD (2010) In vitro method of diagnosis of a demyelinating disease subtype. Patent 0104 - P1982ZA00

Krayenbuehl PA, Maly FE, Hersberger M, Wiesli P, Himmelmann A, Eid K, Greminger P, Vetter W, Schulthess G (2006) Tumor necrosis factor-alpha $-308 \mathrm{G}>\mathrm{A}$ allelic variant modulates iron accumulation in patients with hereditary hemochromatosis. Clin Chem 52:1552-1558

Kurtzke JF (1983) Rating neurologic impairment in multiple sclerosis: an expanded disability status scale (EDSS). Neurology 33:1444 1452
Lefebvre d'Hellencourt C, Montero-Menei CN, Bernard R, Couez D (2003) Vitamin D3 inhibits proinflammatory cytokines and nitric oxide production by the EOC13 microglial cell line. J Neurosci Res 71:575-582

Levenson CW, Cutler RG, Ladenheim B, Cadet JL, Hare J, Mattson MP (2004) Role of dietary iron restriction in a mouse model of Parkinson's disease. Exp Neurol 190:506-514

Levin LI, Munger KL, O'Reilly EJ, Falk KI, Ascherio A (2010) Primary infection with the Epstein-Barr virus and risk of multiple sclerosis. Ann Neurol 67:824-830

LeVine SM, Chakrabarty A (2004) The role of iron in the pathogenesis of experimental allergic encephalomyelitis and multiple sclerosis. Ann N Y Acad Sci 1012:252-266

Liuzzi GM, Latronico T, Rossano R, Viggiani S, Fasano A, Riccio P (2007) Inhibitory effect of polyunsaturated fatty acids on MMP-9 release from microglial cells-implications for complementary multiple sclerosis treatment. Neurochem Res 32:2184-2193

Logroscino G, Marder K, Graziano J, Freyer G, Slavkovich V, LoIacono N, Cote L, Mayeux R (1997) Altered systemic iron metabolism in Parkinson's disease. Neurology 49:714-717

Logroscino G, Chen H, Wing A, Ascherio A (2006) Blood donations, iron stores, and risk of Parkinson's disease. Mov Disord 21:835-838

Lublin FD, Reingold SC (1996) Defining the clinical course of multiple sclerosis: results of an international survey. National Multiple Sclerosis Society (USA) Advisory Committee on Clinical Trials of New Agents in Multiple Sclerosis. Neurology 46:907-911

Ly JD, Grubb DR, Lawen A (2003) The mitochondrial membrane potential (deltapsi(m)) in apoptosis; an update. Apoptosis 8:115-128

Lynch SG, Fonseca T, LeVine SM (2000) A multiple course trial of desferrioxamine in chronic progressive multiple sclerosis. Cell Mol Biol (Noisy-le-grand) 46:865-869

Marder K, Logroscino G, Tang MX, Graziano J, Cote L, Louis E, Alfaro B, Mejia H, Slavkovich V, Mayeux R (1998) Systemic iron metabolism and mortality from Parkinson's disease. Neurology 50:1138-1140

Mastorodemos V, Nikolakaki H, Tzagournissakis M, Kotzamani D, Panou T, Spanaki C, Klados G, Maris T, Kontolaimaki E, Psaroudaki K, Chlouverakis G, Georgakakis G, Plaitakis A (2010) Benign multiple sclerosis in Crete. Mult Scler 16:701-706

Matsushima GK, Morell P (2001) The neurotoxicant, cuprizone, as a model to study demyelination and remyelination in the central nervous system. Brain Pathol 11:107-116

Michaeli S, Oz G, Sorce DJ, Garwood M, Ugurbil K, Majestic S, Tuite $P$ (2007) Assessment of brain iron and neuronal integrity in patients with Parkinson's disease using novel MRI contrasts. Mov Disord 22:334-340

Miravalle A, Corboy JR (2010) Therapeutic options in multiple sclerosis: five new things. Neurology 75:S22-S27

Morath DJ, Mayer-Pröschel M (2001) Iron modulates the differentiation of a distinct population of glial precursor cells into oligodendrocytes. Dev Biol 237:232-243

Morath DJ, Mayer-Pröschel M (2002) Iron deficiency during embryogenesis and consequences for oligodendrocyte generation in vivo. Dev Neurosci 24:197-207

Morell P, Jurevics H (1996) Origin of cholesterol in myelin. Neurochem Res 21:463-470

Munger KL, Chitnis T, Ascherio A (2009) Body size and risk of MS in two cohorts of US women. Neurology 73:1543-1550

Neveu I, Naveilhan P, Menaa C, Wion D, Brachet P, Garabédian M (1994) Synthesis of 1,25-dihydroxyvitamin D3 by rat brain macrophages in vitro. J Neurosci Res 38:214-220

Newman B (2006) Iron depletion by whole-blood donation harms menstruating females: the current whole-blood-collection paradigm needs to be changed. Transfusion 46:1667-1681

Nordvik I, Myhr KM, Nyland H, Bjerve KS (2000) Effect of dietary advice and n-3 supplementation in newly diagnosed MS patients. Acta Neurol Scand 102:143-149 
Owens GP, Bennett JL, Lassmann H, O'Connor KC, Ritchie AM, Shearer A, Lam C, Yu X, Birlea M, DuPree C, Williamson RA, Hafler DA, Burgoon MP, Gilden D (2009) Antibodies produced by clonally expanded plasma cells in multiple sclerosis cerebrospinal fluid. Ann Neurol 65:639-649

Perron H, Lang A (2010) The human endogenous retrovirus link between genes and environment in multiple sclerosis and in multifactorial diseases associating neuroinflammation. Clin Rev Allergy Immunol 39:51-61

Pittock SJ, McClelland RL, Mayr WT, Jorgensen NW, Weinshenker BG, Noseworthy J, Rodriguez M (2004) Clinical implications of benign multiple sclerosis: a 20 -year population-based follow-up study. Ann Neurol 56:303-306

Pittock SJ, Rodriguez M (2008) Benign multiple sclerosis: a distinct clinical entity with therapeutic implications. Curr Top Microbiol Immunol 318:1-17

Pleasure D, Abramsky O, Silberberg D, Quinn B, Parris J, Saida T (1977) Lipid synthesis by an oligodendroglial fraction in suspension culture. Brain Res 134:377-382

Poloni G, Minagar A, Haacke EM, Zivadinov R (2011) Recent developments in imaging of multiple sclerosis. Neurologist 17:185-204

Ramagopalan SV, Cukjati M, Cernilec M, DeLuca GC, Dyment DA, Degenhardt A, Sadovnick AD, Serbec VC, Ebers GC, Duquette P (2008a) Mutations in the hemochromatosis gene and the clinical outcome of multiple sclerosis. J Neuroimmunol 203:104-107

Ramagopalan SV, Deluca GC, Morrison KM, Herrera BM, Dyment DA, Lincoln MR, Orton SM, Chao MJ, Degenhardt A, Pugliatti M, Sadovnick AD, Sotgiu S, Ebers GC (2008b) Analysis of 45 candidate genes for disease modifying activity in multiple sclerosis. J Neurol 255:1215-1219

Ramagopalan SV, Ebers GC (2009) Multiple sclerosis: major histocompatibility complexity and antigen presentation. Genome Med 1:105

Ramagopalan SV, Knight JC, Ebers GC (2009) Multiple sclerosis and the major histocompatibility complex. Curr Opin Neurol 22:219-225

Ramagopalan SV, Dyment DA, Cader MZ, Morrison KM, Disanto G, Morahan JM, Berlanga-Taylor AJ, Handel A, De Luca GC, Sadovnick AD, Lepage P, Montpetit A, Ebers GC (2011) Ann Neurol 70:881-886

Reekers JA, Lee MJ, Belli AM, Barkhof F (2011) Cardiovascular and interventional radiological society of europe commentary on the treatment of chronic cerebrospinal venous insufficiency. Cardiovasc Intervent Radiol 34:1-2

Ristić S, Lovrecić L, Brajenović-Milić B, Starcević-Cizmarević N, Jazbec SS, Sepcić J, Kapović M, Peterlin B (2005) Mutations in the hemochromatosis gene (HFE) and multiple sclerosis. Neurosci Lett 383:301-304

Rodrigue KM, Haacke EM, Raz N (2011) Differential effects of age and history of hypertension on regional brain volumes and iron. Neuroimage 54(2):750-759

Rodriguez M (2009) Have we finally identified an autoimmune demyelinating disease? Ann Neurol 66:572-573

Rooney RN, Kotze MJ, de Villiers JN, Hillermann R, Cohen JA (1999) Multiple sclerosis, porphyria-like symptoms, and a history of iron deficiency anaemia in a family of Scottish descent. Am J Med Genet 86:194-196

Rubio JP, Bahlo M, Tubridy N, Stankovich J, Burfoot R, Butzkueven H, Chapman C, Johnson L, Marriott M, Mraz G, Tait B, Wilkinson C, Taylor B, Speed TP, Foote SJ, Kilpatrick TJ (2004) Extended haplotype analysis in the HLA complex reveals an increased frequency of the HFE-C282Y mutation in individuals with multiple sclerosis. Hum Genet 114:573580
Schwartz R, Datta S (1989) Autoimmunity and autoimmune diseases. In: Paul W (ed) Fundamental immunology, 2nd edn. Raven, New York, pp 819-866

Selzer RR, Rosenblatt DS, Laxova R, Hogan K (2003) Adverse effect of nitrous oxide in a child with 5,10-methylenetetrahydrofolate reductase deficiency. N Engl J Med 349:45-50

Sfagos C, Makis AC, Chaidos A, Hatzimichael EC, Dalamaga A, Kosma K, Bourantas KL (2005) Serum ferritin, transferrin and soluble transferrin receptor levels in multiple sclerosis patients. Mult Scler 11:272-275

Singh AV, Zamboni P (2009) Anomalous venous blood flow and iron deposition in multiple sclerosis. J Cereb Blood Flow Metab 29:1867-1878

Sriram S, Steiner I (2005) Experimental allergic encephalomyelitis: a misleading model of multiple sclerosis. Ann Neurol 58:939-945

Steiner I, Mosberg-Galili R (2010) Quo vadis multiple sclerosis? Inflammopharmacology 18:261-262

Steiner I, Wirguin I (2000) Multiple sclerosis - in need of a critical reappraisal. Med Hypotheses 54:99-106

Strasser-Fuchs S, Enzinger C, Ropele S, Wallner M, Fazekas F (2008) Clinically benign multiple sclerosis despite large T2 lesion load: can we explain this paradox? Mult Scler 14:205-211

Sundström P, Nyström L, Hallmans G (2008) Smoke exposure increases the risk for multiple sclerosis. Eur J Neurol 15:579-583

Sundqvist E, Bäärnhielm M, Alfredsson L, Hillert J, Olsson T, Kockum I (2010) Confirmation of association between multiple sclerosis and CYP27B1. Eur J Hum Genet 18:1349-1352

Suominen P, Punnonen K, Rajamäki A, Irjala K (1998) Serum transferrin receptor and transferrin receptor-ferritin index identify healthy subjects with subclinical iron deficits. Blood 92:2934-2939

Surtees R, Leonard J, Austin S (1991) Association of demyelination with deficiency of cerebrospinal-fluid S-adenosylmethionine in inborn errors of methyl-transfer pathway. Lancet 338:1550-1554

The International Multiple Sclerosis Genetics Consortium \& the Wellcome Trust Case Control Consortium 2 (2011) Genetic risk and a primary role for cell-mediated immune mechanisms in multiple sclerosis. Nature 476:214-219

Todorich B, Pasquini JM, Garcia CI, Paez PM, Connor JR (2009) Oligodendrocytes and myelination: the role of iron. Glia $57: 467-478$

Todorich B, Zhang X, Connor JR (2011) H-ferritin is the major source of iron for oligodendrocytes. Glia 59:927-935

Trapp BD (2004) Pathogenesis of multiple sclerosis: the eyes only see what the mind is prepared to comprehend. Ann Neurol 55:455-457

Ungley CC, Campbell H (1951) Effect of vitamin B12c in pernicious anemia and subacute combined degeneration of the cord. Br Med J 1(4699):152-157

van Rensburg SJ, Haug PD, Kotze M (2009/2010) Multiple sclerosis. In: Snyman JR, Strydom L (eds) MIMS disease review. MIMS (Avusa Media Limited), Saxonwold, South Africa, pp 369-374

van Rensburg SJ, Kotze MJ, Hon D, Haug P, Kuyler J, Hendricks M, Botha J, Potocnik FC, Matsha T, Erasmus RT (2006) Iron and the folate-vitamin B12-methylation pathway in multiple sclerosis. Metab Brain Dis 21:121-137

van Rensburg SJ, van Toorn R (2010) The controversy of CCSVI and iron in multiple sclerosis: is ferritin the key? Neurology 75:15811582

van Rensburg SJ, van Zyl J, Hon D, Daniels W, Hendricks J, Potocnik F, Erasmus R (2004) Biochemical model for inflammation of the brain: the effect of iron and transferrin on monocytes and lipid peroxidation. Metab Brain Dis 19:97-112

van Toorn R, Schoeman JF, Solomons R, Rensburg MA, van Rensburg SJ (2010) Iron status in children with recurrent episodes of tumefactive cerebral demyelination. J Child Neurol 25:1401-1407 
Voet D, Voet JG (2004) Biochemistry. Wiley International Edition, John Wiley, Hoboken

Walther EU, Hohlfeld R (1999) Multiple sclerosis: side effects of interferon beta therapy and their management. Neurology 53:1622-1627

Warren SA, Svenson LW, Warren KG (2008) Contribution of incidence to increasing prevalence of multiple sclerosis in Alberta, Canada. Mult Scler 14:872-879

Weinstock-Guttman B, Zivadinov R, Qu J, Cookfair D, Duan X, Bang E, Bergsland N, Hussein S, Cherneva M, Willis L, HeininenBrown M, Ramanathan M (2011) Vitamin D metabolites are associated with clinical and MRI outcomes in multiple sclerosis patients. J Neurol Neurosurg Psychiatry 82:189-195

Wekerle H, Hohlfeld R (2010) Molecular oracles for multiple sclerosis therapy. Nat Med 16:376-377
Worthington V, Killestein J, Eikelenboom MJ, Teunissen CE, Barkhof F, Polman CH, Uitdehaag BM, Petzold A (2010) Normal CSF ferritin levels in MS suggest against etiologic role of chronic venous insufficiency. Neurology 75:16171622

Yang Y, Sun R, Yang H, Zheng F, Gong F (2010) 308 G > A of TNF- $\alpha$ gene promoter decreases the risk of multiple sclerosis: a metaanalysis. Mult Scler 17:658-665

Zamboni P (2006) The big idea: iron-dependent inflammation in venous disease and proposed parallels in multiple sclerosis. J R Soc Med 99:589-593

Zhang X, Surguladze N, Slagle-Webb B, Cozzi A, Connor JR (2006) Cellular iron status influences the functional relationship between microglia and oligodendrocytes. Glia 54:795-804 